Working Paper/Document de travail 2010-23

\title{
Central Bank Haircut Policy
}

\author{
by James Chapman, Jonathan Chiu, and Miguel Molico
}


Bank of Canada Working Paper 2010-23

October 2010

\title{
Central Bank Haircut Policy
}

\author{
by
}

\author{
James Chapman, ${ }^{1}$ Jonathan $\mathrm{Chiu}^{2}{ }^{2}$ and Miguel Molico ${ }^{2}$ \\ ${ }^{1}$ Financial Stability Department \\ 2Funds Management and Banking Department \\ Bank of Canada \\ Ottawa, Ontario, Canada K1A 0G9 \\ jchapman@bankofcanada.ca \\ jchiu@bankofcanada.ca \\ mmolico@bankofcanada.ca
}

Bank of Canada working papers are theoretical or empirical works-in-progress on subjects in economics and finance. The views expressed in this paper are those of the authors. No responsibility for them should be attributed to the Bank of Canada. 


\section{Acknowledgements}

We have benefited from the comments and suggestions of Mitchell Berlin, Lindsay Cheung, Alejandro Garcia, Charles Kahn, Cyril Monnet, Enchuan Shao and Brett Stuckey as well as participants in seminars at the Bank of Canada, Bank of England and The Workshop on Central Bank Liquidity Tools at the Federal Reserve Bank of New York, The Far Eastern 2009 Summer Meetings of Econometric Society and The 2009 Workshop on Money and Payments at the Federal Reserve Bank of New York. 


\begin{abstract}
We present a model of central bank collateralized lending to study the optimal choice of the haircut policy. We show that a lending facility provides a bundle of two types of insurance: insurance against liquidity risk as well as insurance against downside risk of the collateral. Setting a haircut therefore involves balancing the trade-off between relaxing the liquidity constraints of agents on one hand, and increasing potential inflation risk and distorting the portfolio choices of agents on the other. We argue that the optimal haircut is higher when the central bank is unable to lend exclusively to agents who actually need liquidity. Finally, for an unexpected drop in the haircut, the central bank can be more aggressive than when setting a permanent level of the haircut.

JEL classification: E40, E50

Bank classification: Payment, clearing, and settlement systems; Central bank research; Monetary policy implementation; Financial system regulation and policies; Financial services
\end{abstract}

\title{
Résumé
}

Les auteurs étudient la politique de décote optimale à l'aide d'un modèle formalisant l'octroi par la banque centrale de prêts contre garantie. Ils montrent qu'une facilité de prêt offre une assurance à la fois contre le risque de liquidité et contre le risque de baisse de la valeur de la garantie. L'établissement du niveau de la décote suppose donc un arbitrage entre, d'une part, le desserrement des contraintes de liquidité des agents et, d'autre part, le risque de faire augmenter l'inflation et de fausser les choix de portefeuille des agents. Les auteurs soutiennent que la décote optimale est plus élevée lorsque la banque centrale n'est pas en mesure de limiter exclusivement ses prêts aux agents qui ont réellement besoin de liquidités. Enfin, quand elle abaisse la décote de façon inattendue, la banque centrale a plus de latitude que lorsqu'elle en fixe durablement le niveau.

Classification JEL : E40, E50

Classification de la Banque : Systèmes de paiement, de compensation et de règlement; Recherches menées par les banques centrales; Mise en œuvre de la politique monétaire; Réglementation et politiques relatives au système financier; Services financiers 


\section{Introduction}

In this paper we examine how a central bank should make loans of a liquid asset (in this case central bank reserve money) that are collateralized by illiquid and risky assets. This is an important question since in an economy with trading frictions and idiosyncratic liquidity shocks, two empirically relevant features, the equilibrium allocation is typically inefficient due to some agents being liquidity constrained due to their ex-post excessive holding of illiquid assets. With trading frictions (and hence illiquid assets) this inefficiency leads to a role for a central bank in creating and distributing liquidity. In such an economy, a benevolent central bank may desire to provide liquidity to constrained agents by using a lending facility. When there is a lack of perfect enforcement of these loans, illiquid assets can be taken as collateral for loans. However, the value of this collateral can change over time and it is therefore necessary to require a pledge of collateral large enough to adequately cover losses in the event of a default (i.e. by setting a positive haircut). ${ }^{1}$ This facility is similar to that studied by Berentsen and Monnet (2008) with the exception that we relax their assumption of perfect enforcement.

When a lender seeks to make a collateralized loan to a borrower, the value of the collateral is usually subject to a discount or "haircut" to ensure that in the event of a default the collateral can be liquidated to repay a sufficient amount of the loan; since the price of the collateralized asset may have declined in the intervening period. The typical way these haircuts are calculated in the private sector (which we term a risk-management approach) is via an examination of the historical volatility of the value of the collateral and setting a haircut to limit the risk exposure of the lender. ${ }^{2}$ This risk-management approach is an appropriate methodology for a market participant who has little market

\footnotetext{
${ }^{1}$ In addition, the haircut has to be sufficient to induce the lender to repay the loan and not default if strategic default is allowed as shown by Lacker (2001).

${ }^{2}$ See, for example, Garcia and Gençay (2006, section 6.2) and related risk management literature referenced therein.
} 
power and aims at maximizing its own profit. We argue in this paper that the typical risk-management approach to setting the haircuts is not appropriate for a central bank. We base this conclusion on the fact that a central bank is a large market participant in the interbank market as well as other funding markets; it is benevolent in that it cares about the efficiency and stability of the financial system instead of its own profits; and finally it has the unique ability to create liquid assets in the form of central bank liabilities. Therefore, a central bank, when it sets haircuts, must take into account the effect its operations will have on the incentives and decisions of other financial market participants.

We use a model that captures the main features of such a lending facility to study the general equilibrium effects of the haircut on the consumption and portfolio decisions of agents, equilibrium asset prices, aggregate welfare, and also the default decision of central bank borrows. ${ }^{3}$ We find two key elements in determining the optimal level of the haircut.

First, there is a trade-off between liquidity and default risk. A lending facility provides a bundle of two insurances: insurance against liquidity risk and also an insurance against the downside risk of illiquid asset. ${ }^{4}$ Lowering a haircut relaxes the liquidity constraint of the illiquid portfolio holders (which can be welfare improving if the constraint is binding). On the other hand, it also provides the borrowers an option to shift the investment loss to the central bank when the value of the asset turns out to be low (which is not welfare improving). As a result, decreasing the haircut will make the illiquid, risky asset more attractive and may distort agents' portfolio choices, inducing an agent with high need for liquidity to hold a portfolio which is illiquid and risky.

Second, lowering the haircut will increase the exposure of the central bank

\footnotetext{
${ }^{3}$ We take as given the features of the standing lending facility (i.e. collateralized loans subject to a haircut) and focus on the determination of the optimal haircut policy. These features are meant to capture properties of existing lending facilities (e.g., the broad institutional framework of the Canadian Large Value Payment System (LVTS)). Designing an optimal setup of the lending facility is not the goal of the paper.

${ }^{4} \mathrm{~A}$ reader may think of downside risk as market risk. We use the term downside risk to highlight the moral hazard aspects of providing this insurance.
} 
to losses and hence potentially increases in expected inflation. When lump-sum taxation is not an instrument available to the central bank, liquidity loaned out for payment may not be fully re-absorbed if the borrowers default. This will increase potential inflation which in turn increases the equilibrium opportunity costs of holding liquid assets, and therefore tightens the liquidity constraints of holders of the liquid asset.

We also point out that one key factor is whether the central bank is able to lend exclusively to agents who actually need liquidity. ${ }^{5}$ When exclusive lending is not feasible, the cost of providing liquidity insurance to the illiquid asset holders by lowering the haircut becomes more costly in terms of distorting the liquid asset holders' liquidity constraint. Owing to this trade-off, it is generally not optimal to set the haircut too low. Finally, we also illustrate that, if the central bank can commit not to repeat in the future, a temporary, surprise cut in the haircut can be welfare improving.

Our model is related to the recent literature that deals with how the central bank's operating procedures can affect the allocation of the economy. Specifically our paper is closely related to the papers by Berentsen and Monnet (2008) and Martin and Monnet (2008). Examples of related work in this area are Chapman and Martin (2007), Khan (2008) and Suárez-Lledó (2009).

The rest of the paper is organized as follows. Section 2 describes the model environment. Section 3 derives and characterizes the equilibrium and discusses the policy constraint faced by the central bank. Section 4 focuses on a special type of equilibria where agents specialize in their asset portfolio choices and derives some analytical and numerical result. Section 5 considers more general cases and discusses optimal haircut policy. Section 6 provides some discussion on endogeneizing the amount of pledgeable assets. Finally, we provide some concluding remarks in section 7 .

\footnotetext{
${ }^{5}$ The recent literature has made a distinction between funding and market liquidity. In this paper, the liquidity of our model can be thought of as market liquidity.
} 


\section{Model}

Before going into the formal setup and analysis, we will first provide an overview of the model and discuss how it maps to the real world, in particular, how it captures key features of existing payment systems, like the Canadian Large Value Transfer System (LVTS).

\subsection{Overview}

The model builds on four key features of payment systems to motivate the role of the haircut policy. First, payment system participants face a non-trivial portfolio choice between holding liquid and illiquid assets. Liquid assets are needed to send payments in the payment systems. Illiquid assets yield a higher return and are generally riskier. Second, participants face uncertainty regarding their liquidity needs, modeled here as idiosyncratic liquidity shocks realized after agents make their portfolio choice. Some participants may end up holding too much illiquid assets when they are facing a high liquidity need. In the absence of intraday interbank money market, there is a role for a central bank lending facility. ${ }^{6}$ Third, these loans are subject to potential default by the borrowers. This motivates the need to require borrowers to pledge collateral. Fourth, the asset price of the collateral is uncertain. This generates the need to impose a haircut on the collateral.

Our model is based on the alternating market formulation of Lagos and Wright (2005), and liquidity shocks of Berentsen and Monnet (2008). This allows us to study frictions in the interbank market but still have frictionless trade in the asset market. We will use this model to study how changing the haircut policy will induce the endogenous response of default and portfolio choice. $^{7}$

\footnotetext{
${ }^{6}$ Martin and McAndrews (2008) discuss the lack of an intraday market for reserves and present arguments for and against such a market.

${ }^{7}$ The Lagos-Wright framework can allow us to analyze the question in a relatively tractable fashion, by eliminating the wealth effects of idiosyncratic trading histories. Moreover, as
} 


\subsection{Environment}

Time is discrete and denoted $t=0,1,2, \ldots$ In this economy, there is a measure one continuum of anonymous, infinitely lived agents. As in Berentsen and Monnet (2008), one can interpret each of these agents as a consolidated unit consisting of a bank and its clients. ${ }^{8}$

Each period is divided into three consecutive subperiods. In the first subperiod, an asset market (denoted by AM) is open where agents (banks) make portfolio choice between liquid and illiquid assets. The asset market remains open during the following subperiods. In the second subperiod, a decentralized market (denoted by DM) opens where agents trade goods against the liquid assets. We interpret this market as banks sending payments to each other in the payment system to settle the goods transactions among their underlying clients. The DM and the AM are segmented, in the sense that DM participants do not have access to the AM during the second subperiod. ${ }^{9}$ With probability $1-\alpha$ the agent participates in the DM market, with probability $\alpha$ and agents remains in the asset market. ${ }^{10}$ In the DM the central bank provides intraday collateralized loans to agents subject to a haircut. ${ }^{11}$ In the third subperiod, agents enter a centralized market (denoted CM) to trade a numeraire good and to settle their intraday loans with the central bank. The basic setup of these markets is described in figure 1.

argued in Koeppl, Monnet and Temzelides (2008), the Lagos-Wright setup well captures the feature of periodic settlement in a payment systems.

${ }^{8}$ We think that modeling the bank-client relationship explicitly is interesting, but may not be of first order importance for the main question of the paper. We will leave this extension for future research.

${ }^{9}$ This assumption is meant to capture the absence of an intraday interbank market and provides a role for central bank liquidity provision.

${ }^{10}$ In the second subperiod, we only need some trade in the asset market to pin down the price of the asset. For this purpose, $\alpha$ has to be non-zero, but can be arbitrarily small.

${ }^{11}$ While we model the role of collateralized intra-day loans to buyers, we abstract from the possibility of sellers earning interest on their idle balances. Potentially, one can incorporate this feature by introducing an intra-day interbank market, or having the central bank operating a paying interest on reserve deposit. This tends to increase the value of holding money balances and reduces the distortion of inflation, as already pointed out by the existing literature (e.g., Berentsen, Camera and Waller (2005), Berentsen and Monnet (2008)). 


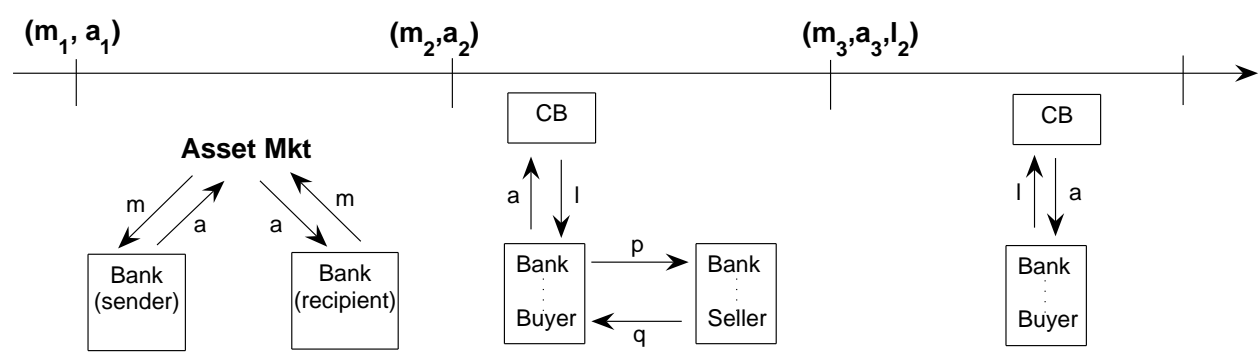

Figure 1: Timeline of Markets and Actions in a Given Period $t$

We are going to consider a stationary environment. The per-period utility of an agent is given by

$$
u\left(q_{2}^{b}\right)-q_{2}^{s}-H_{3},
$$

where $q_{2}^{b} \in \mathbb{R}_{+}$denotes the consumption of the DM goods when the agent is a buyer, and $q_{2}^{s} \in \mathbb{R}_{+}$denotes the production of the DM goods when the agent is a seller in the second subperiod. $u: \mathbb{R}_{+} \rightarrow \mathbb{R}$ denotes the utility of consuming $q$ units of the DM goods. $H_{3} \in \mathbb{R}$ denotes the production (net of consumption) of the CM goods. We assume that $u($.$) is twice continuously differentiable,$ strictly increasing, strictly concave, satisfies $u(0)=0, u^{\prime}(0)=\infty, u^{\prime}(\infty)=0$, $u^{\prime}\left(q^{*}\right)=1$ for some $q^{*}>0$.

To introduce an interesting portfolio choice into the model, we assume that there are two assets: a liquid asset and an illiquid asset. The liquid asset is the only asset that is acceptable as a means of payment in the DM. It is denoted by $m_{t}$ and can be interpreted as fiat money or bank reserves. Money is perfectly divisible, costlessly storable, and cannot be produced or consumed by any private agent. The supply of the stock of this asset is controlled by the central bank. The central bank injects money by non-negative lump-sum transfers. An important assumption is that the central bank is not able to make negative money transfers (i.e. lump-sum taxation). Money pays no dividend.

The illiquid asset is denoted by $a_{t}$. It is illiquid because it cannot be used as a means of payment in the DM. One can interpret it as claims to invest- 
ment projects held by the agents. For simplicity, we assume that each agent is endowed with $A$ one-period projects at the beginning of a period. Each unit of asset yields real dividend $\delta_{t}$ (in terms of CM numeraire goods) at the end of the period $t$ CM. To introduce the feature of asset price uncertainty, we assume that $\delta$ is a random i.i.d. (owner specific) variable, drawn from a uniform distribution over the support $[\bar{\delta}(1-\varepsilon), \bar{\delta}(1+\varepsilon)]$, and with mean $\bar{\delta}<1$. The prices of these projects are denoted by $\psi: \psi_{1}$ is the nominal price of the asset in the subperiod $1 \mathrm{AM} ; \psi_{2}$ is the nominal value of the dividend of the asset in the subperiod $2 \mathrm{AM}$; and $\psi_{3}$ is the price in the subperiod $3 \mathrm{CM}$ after the realization of $\delta$ (before the dividend is paid).

\section{Sequence of Events}

Figure 2 shows the timeline of the model. At the beginning of each period, each agent receives a noisy signal which suggests whether an agent is likely to be a payment sender (buyer) in the DM (i.e. high liquidity need), or likely to be a payment recipient (seller) in the DM (i.e. low liquidity need). Given the signal, agents trade in the AM and make portfolio choices of liquid asset $m$ and illiquid asset $a$. Typically, an agent expecting a high liquidity need will choose to hold more liquid asset, and one expecting a low liquidity need will choose a more illiquid portfolio.

To introduce idiosyncratic liquidity shocks, we assume that the signal will turn out to be incorrect with a positive probability $\theta$. In particular, after the portfolio choice is made, an agent enters the DM with probability $1-\alpha$ and observes the realization of his/her trading status: buyer (i.e. payment sender) or a seller (i.e. payment recipient). In a bilateral meeting, the buyer makes a take-it-or-leave-it offer $(q, p)$ to the seller, where $q$ denotes the quantity of goods and $p$ denotes the quantity of money to be traded. Since trading in the DM is subject to a liquidity constraint (only $m$ is acceptable as means of payment), some agents will end up holding too much illiquid asset when they want to 


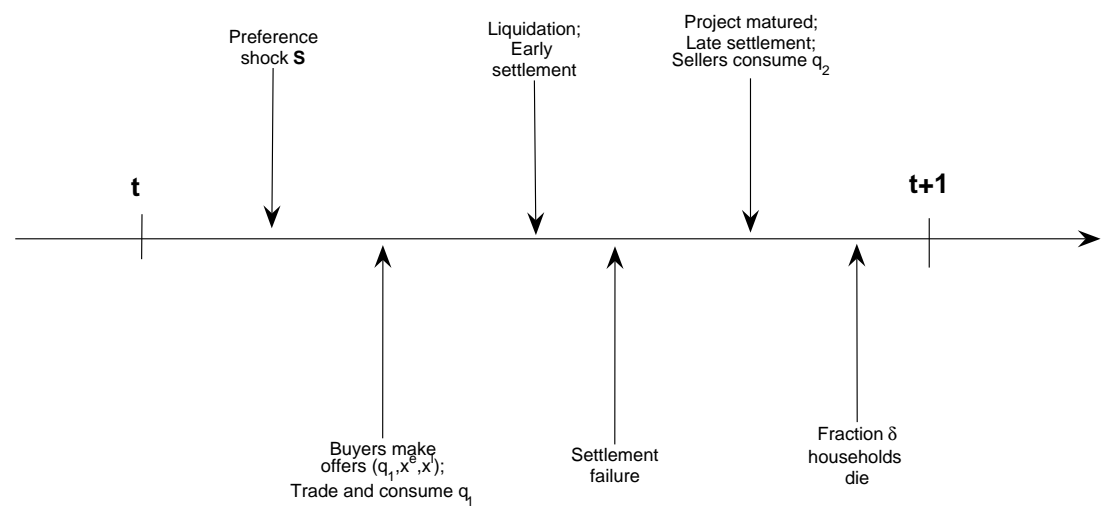

Figure 2: Sequence of Events during a period $t$

purchase goods. Their liquidity constraints can be relaxed by borrowing from the central bank's intraday lending facility by posting the asset as collateral. Before trade, buyers (but not sellers or asset traders) have access to central bank standing facilities. The intraday interest rate is zero. ${ }^{12}$ The borrowing constraint in nominal terms is set by the central bank:

$$
l_{2} \leq a_{2} \psi_{2}(1-h)
$$

where $h$ denotes the haircut imposed on the collateral. This loan has to be settled in the $\mathrm{CM}$ in the third subperiod. To introduce the role of strategic default, we assume that at the beginning of the $\mathrm{CM}$, the values of all projects become public information, and after that borrowers decide whether to settle

\footnotetext{
${ }^{12}$ The zero interest assumption is motivated by the fact that the intra-day interest rate in most payment systems are zero or very close to zero. For example, Bhattacharya et al. (2009) reported that "In most countries, the cost of reserves intraday is very close to zero. Many central banks, including the European Central Bank (ECB), the Bank of England, or the Swiss National Bank allow collateralized intraday borrowing at no cost. In the U.S., banks are allowed to incur uncollateralized daylight overdrafts for which they incur a small fee."
} 


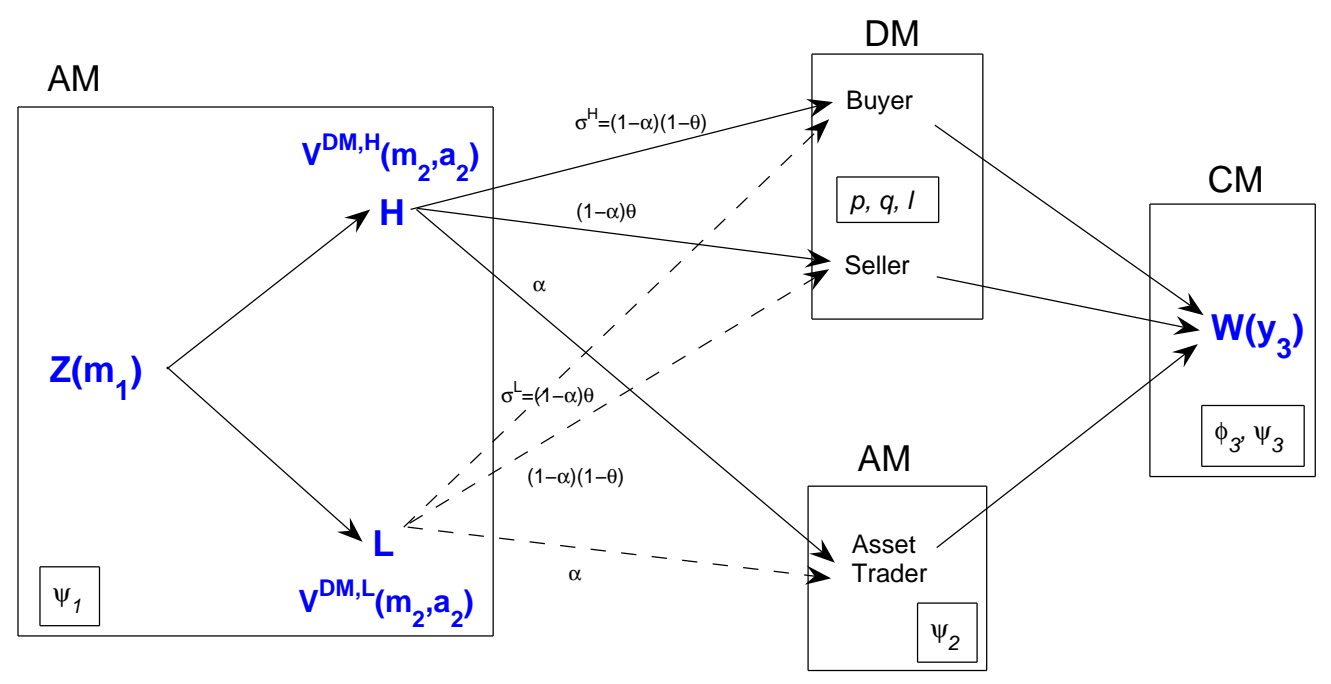

Figure 3: Flows of Agents

the loan (and get back the asset) or to default (and lose the asset). ${ }^{13}$ In the absence of additional punishment device, a borrower who has pledged asset $a$ and borrowed $l$ will default if the realization of the asset value is low, $l \geq a \psi_{3}{ }^{14}$ Figure 3 illustrates the flow of agents across states.

\section{Equilibrium}

We are going to solve the model backwards: first solving for the CM problem in subperiod 3, then the DM and AM problems in subperiod 2, and finally the AM problem in subperiod 1.

\footnotetext{
${ }^{13}$ Although in the presence of asset price uncertainty the assumption of strategic default seems natural, it is not essential for most of our results.

${ }^{14}$ In general, one can assume that default also involves a cost of $R$ (e.g. punishment, reputation cost). As a result, an agent will default only if $l \geq a \psi_{3}+R$. When $R$ is a finite number, agents may still strategically default. When $R=+\infty$, agents have perfect commitment. When $R$ is drawn randomly from the set $\{-\infty,+\infty\}$, then it is exogenous default. Furthermore, agents are assumed to be anonymous, so the central bank or other agents cannot induce repayment by future punishment (e.g. forever autarky). One may relax this assumption and endogenize the value of $R$.
} 


\section{Subperiod 3: Centralized Market}

In the $\mathrm{CM}$, agents observe the payoffs of the assets $\left(\delta_{t}\right)$ and then choose whether to default and money holding $\left(m_{+1}\right)$ for the following AM. We use the subscript +1 to denote values during the next period. The price of money in terms of $\mathrm{CM}$ goods is $\phi_{3}$. We use $y_{3}$ to denote the real value of wealth an agent brings to the CM (which is the real value of the money and assets in his portfolio after the default decision, and will be derived below). After deciding whether to default, an agents' optimization problem is to choose production $H_{3}$, and money holding $m_{+1}$ to maximize payoff:

$$
W\left(y_{3}\right)=\max _{H_{3}, m_{+1}}-H_{3}+\beta Z_{+1}\left(m_{+1}\right)
$$

subject to

$$
-H_{3}=y_{3}-\phi_{3} m_{+1}+\phi_{3} \Delta M
$$

Here, $\Delta M=M_{+1}-M_{3}$ with $M_{3}$ and $M_{+1}$ being the total money stock at the beginning and at the end of subperiod 3 respectively. $Z_{+1}$ is the value function for next period's AM market. The linearity of utility implies that

$$
W\left(y_{3}\right)=\max _{m_{+1}} y_{3}-\phi_{3} m_{+1}+\phi_{3} \Delta M+\beta Z_{+1}\left(m_{+1}\right)
$$

F.O.C.:

$$
m_{+1}: \phi_{3} \geq \beta \frac{\partial}{\partial m_{+1}} Z_{+1}\left(m_{+1}\right),=\text { if } m_{+1}>0
$$

Note that the choice of $m_{+1}$ is independent of $y_{3}$. We will focus on symmetric equilibrium with $m_{+1}=M_{+1}$ for all agents, so that the distribution of money holding at the beginning of each period is degenerate. The envelope condition is given by

$$
W^{\prime}\left(y_{3}\right)=1
$$




$$
W\left(y_{3}\right)=W(0)+y_{3}
$$

In principle, agents can also trade their assets in the CM, but they do not have incentive to do so because of the linear utility. In particular, the no-arbitrage condition implies that an asset which is going to deliver $\delta$ units of goods at the end of the period has a nominal price $\psi_{3}(\delta)=\delta / \phi_{3}$. The following lemma summarizes the result.

Lemma 1. The CM problem implies

(i) $W(y)$ is linear in $y$, with $W^{\prime}(y)=1$;

(ii) All agents choose the same $m_{+1}=M_{+1}$;

(iii) $\psi_{3}(\delta)=\delta / \phi_{3}$.

\section{Subperiod 2: Asset Market and Decentralized Market}

In subperiod 2 , agents start with money holding $m_{2}$ and asset holding $a_{2}$. There is a shock that determines an agent's trading status. With a probability $\alpha$, an agent enters the AM as an asset trader. With a probability $1-\alpha$, an agent enters the DM as a goods trader.

When an agent enters the AM as an asset trader, his optimization problem is given by

$$
V^{A M}\left(m_{2}, a_{2}\right)=\max _{m_{3}, a_{3}} W\left(y_{3}\right)=\phi_{3} m_{3}+\phi_{3} E\left(\psi_{3}\right) a_{3}+W(0)
$$

subject to

$$
m_{2}+\psi_{2} a_{2}=m_{3}+\psi_{2} a_{3}
$$

F.O.C.s:

$$
\begin{aligned}
& m_{3}: \quad \lambda_{2} \geq 1,=\text { if } m_{3}>0 \\
& a_{3}: \quad \lambda_{2} \psi_{2} \geq E\left(\psi_{3}\right),=\text { if } \quad a_{3}>0
\end{aligned}
$$


where $\lambda_{2}$ denotes the Lagrangian multiplier. Market clearing conditions imply $\psi_{2}=E\left(\psi_{3}\right)$. Note that the choices $\left(m_{3}, a_{3}\right)$ are independent of $\left(m_{2}, a_{2}\right)$.

$$
\begin{aligned}
V_{m}^{A M}\left(m_{2}, a_{2}\right) & =\phi_{3} \\
V_{a}^{A M}\left(m_{2}, a_{2}\right) & =\phi_{3} E\left(\psi_{3}\right)
\end{aligned}
$$

Therefore,

$$
V^{A M}\left(m_{2}, a_{2}\right)=\phi_{3} m_{2}+\phi_{3} E\left(\psi_{3}\right) a_{2}+W(0)
$$

Trading in AM does not affect the payoff of agents. The following lemma summarizes the result.

Lemma 2. The AM problem implies

(i) $V_{m}^{A M}\left(m_{2}, a_{2}\right)=\phi_{3}$;

(ii) $V_{a}^{A M}\left(m_{2}, a_{2}\right)=\phi_{3} E\left(\psi_{3}\right)$;

(iii) $\psi_{2}=E\left(\psi_{3}\right)$.

Before we consider the DM problem, let's first determine the continuation value in the following CM. At the beginning of the next centralized market, borrowers (i.e. buyers in the DM) observe $\delta$ and $\psi_{3}(\delta)=\delta / \phi_{3}$ and choose whether to pay back $l_{2}$ or to give up the collateral and default. Note that the real wealth at the beginning of the following centralized market is

$y_{3}=\phi_{3}\left[m_{2}-\left(p-l_{2}\right)\right]+\phi_{3} \psi_{3}\left[a_{2}-\frac{l_{2}}{\psi_{2}(1-h)}\right]+\max \left\{\phi_{3} \psi_{3} \frac{l_{2}}{\psi_{2}(1-h)}-\phi_{3} l_{2}, 0\right\}$

That is, the real wealth is equal to the real value of the unspent money holding $\left(\phi_{3}\left(m_{2}-\left(p-l_{2}\right)\right)\right)$, plus real value of the unpledged asset $\left(\phi_{3} \psi_{3}\left[a_{2}-\frac{l_{2}}{\psi_{2}(1-h)}\right]\right)$, plus the potential gain from repaying the loan $\left(\phi_{3} \psi_{3} \frac{l_{2}}{\psi_{2}(1-h)}-\phi_{3} l_{2}\right)$. Note that the agent always has an option to default, in particular it happens when the asset value drops too much (i.e. $\frac{\psi_{3}}{\psi_{2}}$ too low) relative to the haircut (i.e. $\frac{1}{1-h}$ 
too low). Simplifying the above expression, we get

$$
y_{3}=\phi_{3} m_{2}-\phi_{3} p+\phi_{3} \psi_{3} a_{2}+\max \left\{0, \phi_{3} l_{2}-\phi_{3} \psi_{3} \frac{l_{2}}{\psi_{2}(1-h)}\right\}
$$

If the central bank wants to ensure repayment in any circumstances, the following inequality has to be satisfied for any $\delta$ :

$$
\begin{aligned}
\phi_{3} l_{2}-\phi_{3} \psi_{3}(\delta) \frac{l_{2}}{\psi_{2}(1-h)} & \leq 0 \\
\text { or } \frac{\psi_{2}-\psi_{3}(\delta)}{\psi_{2}} & \leq h
\end{aligned}
$$

Therefore, the no-default constraint is particularly binding when $\psi_{3}$ (i.e. $\delta$ ) is low. When $\delta=\bar{\delta}$ in all realization (i.e. $\varepsilon=0$ ), $h$ can be set to zero (no haircut). When $\psi_{3}=0$ in some realization (i.e. $\varepsilon=1$ ), $h$ has to be one (i.e. the asset is not an eligible collateral) to guarantee no-default in all circumstances. In general, if the central bank sets an haircut such that

$$
h<1-\frac{\psi_{3}(\delta)}{\psi_{2}}=1-\frac{\delta}{\bar{\delta}}
$$

then there will be default when $\delta$ is sufficiently low.

As a result,

$$
y_{3}= \begin{cases}\phi_{3} m_{2}-\phi_{3} p+\phi_{3} \psi_{3} a_{2}+l_{2} \max \left\{\phi_{3}-\frac{\phi_{3} \psi_{3}}{\psi_{2}(1-h)}, 0\right\} & , \text { for a buyer } \\ \phi_{3} m_{2}+\phi_{3} p+\phi_{3} \psi_{3} a_{2} & \text {, for a seller }\end{cases}
$$

Therefore, the payoff of a buyer in the DM is

$$
\begin{aligned}
& u(q)+E W(y) \\
= & u(q)+E W(0)+E(y) \\
= & u(q)+E W(0)+\phi_{3} m_{2}-\phi_{3} p+\phi_{3} a_{2} E\left(\psi_{3}\right)+l_{2} E \max \left\{\phi_{3}-\frac{\phi_{3} \psi_{3}}{\psi_{2}(1-h)}, 0\right\} \\
= & u(q)+\text { constant }+\phi_{3} m_{2}-\phi_{3} p+\phi_{3} a_{2} E\left(\psi_{3}\right)+\phi_{3} l_{2} S(h),
\end{aligned}
$$


where $S(h)$ is the option value of default, derived in the following lemma (see appendix A).

Lemma 3. The expected value of the option to default is equal to $S(h)=\frac{(\varepsilon-h)^{2}}{4 \varepsilon(1-h)}$.

Note that, $S \geq 0$ and $S$ is positive whenever $h<\varepsilon$ (i.e. partial haircut). Now, we look at the maximization problem faced by a buyer in the decentralized market when the standing facility is available:

$$
\max _{q, p} u(q)+\left(\phi_{3} m_{2}-\phi_{3} p+\phi_{3} a_{2} E\left(\psi_{3}\right)+\phi_{3} l_{2} S(h)\right)
$$

subject to

$$
\begin{aligned}
& \text { Liquidity constraint }: m_{2}+l_{2} \geq p \\
& \text { Borrowing constraint : } l_{2} \leq \psi_{2} a_{2}(1-h) \\
& \text { Seller's participation constraint }: \quad \phi_{3} p=q
\end{aligned}
$$

Here, assuming buyers have all the bargaining power, the buyer needs to choose the terms of trade $(q, p)$ to maximize the payoff, subject to the liquidity constraint, the borrowing constraint, and the seller's participation constraint. This problem is equivalent to solving

$$
\max _{q, l_{2}} u(q)-q+\phi_{3} l_{2} S(h)
$$

subject to

$$
\begin{aligned}
m_{2}+l_{2} & \geq q / \phi_{3} \\
\psi_{2} a_{2}(1-h) & \geq l_{2}
\end{aligned}
$$

Using $\eta_{m}$ and $\eta_{a}$ to denote the multipliers of the two constraints, then the FOCs 
are given by

$$
\begin{aligned}
q & : \phi_{3}\left(u^{\prime}(q)-1\right)=\eta_{m} \\
l_{2}: & \phi_{3} S(h)+\eta_{m}=\eta_{a}
\end{aligned}
$$

From now on, we will focus on monetary equilibria with $\phi_{3}>0$. The first condition implies that whenever $u^{\prime}(q)>1$, the liquidity constraint is binding. The second condition implies that whenever $S(h)>0$ or $u^{\prime}(q)>1$, the borrowing constraint is binding:

Lemma 4. If $h<\varepsilon$, then $l_{2}=\psi_{2} a_{2}(1-h)$.

That is, whenever the haircut is partial, buyers will borrow up to the borrowing limit to take advantage of the positive option value of default. And the bargaining solution implies

$$
q\left(m_{2}, a_{2}\right)=\left\{\begin{array}{cl}
q^{*}, & \text { if } \phi_{3} m_{2}+\phi_{3} \psi_{2} a_{2}(1-h) \geq q^{*} \\
\phi_{3} m_{2}+\phi_{3} \psi_{2} a_{2}(1-h), & \text { if } \phi_{3} m_{2}+\phi_{3} \psi_{2} a_{2}(1-h)<q^{*}
\end{array}\right.
$$

where $q^{*}$ satisfies $u^{\prime}(q)=1$. Denote the solution by $q\left(m_{2}, a_{2}\right)$.

The value function at the beginning of the second subperiod is simply a weighted sum of the value functions in the AM and the DM:

$$
\begin{aligned}
V^{j}\left(m_{2}, a_{2}\right)= & (1-\alpha) V^{D M, j}\left(m_{2}, a_{2}\right)+\alpha V^{A M}\left(m_{2}, a_{2}\right) \\
= & \phi_{3} m_{2}+\phi_{3} E\left(\psi_{3}\right) a_{2}+W(0)+\sigma^{j}\left[u\left(q\left(m_{2}, a_{2}\right)\right)-q\left(m_{2}, a_{2}\right)\right] \\
& +\sigma^{j}\left[\phi_{3} l_{2} S(h)\right], \text { for } j=H, L,
\end{aligned}
$$

Again, we have shown that $l_{2}=\psi_{2} a_{2}(1-h)$ if $h<\varepsilon$ or if $\phi_{3} m_{2}+\phi_{3} \psi_{2} a_{2}(1-h)<$ 
$q^{*}$. So the envelope conditions are,

$$
\begin{aligned}
V_{m}^{j}\left(m_{2}, a_{2}\right)= & \phi_{3}+\sigma^{j}\left[u^{\prime}\left(q\left(m_{2}, a_{2}\right)\right)-1\right] \phi_{3} 1\left\{\phi_{3} m_{2}+\phi_{3} \psi_{2} a_{2}(1-h)<q^{*}\right\} \\
V_{a}^{j}\left(m_{2}, a_{2}\right)= & \phi_{3} E\left(\psi_{3}\right)+ \\
& \sigma^{j}\left[u^{\prime}\left(q\left(m_{2}, a_{2}\right)\right)-1\right] \phi_{3} \psi_{2}(1-h) 1\left\{\phi_{3} m_{2}+\phi_{3} \psi_{2} a_{2}(1-h)<q^{*}\right\} \\
& +\sigma^{j} \phi_{3} \psi_{2}(1-h) S(h) 1\left\{\phi_{3} m_{2}+\phi_{3} \psi_{2} a_{2}(1-h)<q^{*} \text { or } h<\varepsilon\right\},
\end{aligned}
$$

where $1\{x\}$ is an indicator such that it is one if $x$ is true, and is zero otherwise. We will focus on equilibria in which the liquidity constraints are binding. Therefore, we have the following result:

Lemma 5. Suppose the liquidity constraints are binding in the DM, then

$$
\begin{aligned}
& V_{m}^{j}\left(m_{2}, a_{2}\right)=\phi_{3}+\sigma^{j} \Delta^{j} \phi_{3} \\
& V_{a}^{j}\left(m_{2}, a_{2}\right)=\phi_{3} E\left(\psi_{3}\right)+\sigma^{j}\left[\Delta^{j}+S(h)\right] \phi_{3} \psi_{2}(1-h),
\end{aligned}
$$

where $\Delta^{j}=u^{\prime}\left(q\left(m_{2}, a_{2}\right)\right)-1$.

\section{Subperiod 1: Asset market}

At the beginning of a period, each agent receives a signal $s \in\{H, L\}$. A signal $H$ denotes the case in which the agent will likely become a buyer in the DM (high liquidity need). A signal $L$ denotes the case in which the agent will likely become a seller in the DM (low liquidity need). The signal will turn out to be

incorrect with a probability $\theta<\frac{1}{2}$. Therefore, an agent with a high signal will be a buyer with a probability $\sigma^{H}=(1-\alpha)(1-\theta)$, and an agent with a low signal will be a buyer with a probability $\sigma^{L}=(1-\alpha) \theta$. And an agent will attend the asset market with a probability $\alpha$. After receiving the signal $s$, an agent solves the following portfolio choice problem:

$$
\max _{m_{2}, a_{2}} V^{j}\left(m_{2}^{j}, a_{2}^{j}\right)
$$


subject to

$$
\begin{aligned}
m_{1}+\psi_{1} A & \geq m_{2}^{j}+\psi_{1} a_{2}^{j}\left(\text { with multiplier } \lambda^{j}\right) \\
m_{2}^{j} & \geq 0 \\
a_{2}^{j} & \geq 0 .
\end{aligned}
$$

The first order conditions with respect to $m_{2}$ and $a_{2}$ are give by

$$
\begin{aligned}
& m_{2}^{j}: \quad \lambda^{j} \geq V_{m}^{j}\left(m_{2}^{j}, a_{2}^{j}\right), \quad\left(=\text { if } m_{2}^{j}>0\right) \\
& a_{2}^{j} \quad: \quad \lambda^{j} \psi_{1} \geq V_{a}^{j}\left(m_{2}^{j}, a_{2}^{j}\right), \quad\left(=\text { if } a_{2}^{j}>0\right)
\end{aligned}
$$

And the envelope conditions of the second subperiod are

$$
\begin{aligned}
& V_{m}^{j}\left(m_{2}, a_{2}\right)=\phi_{3}+\sigma^{j} \Delta^{j} \phi_{3} \\
& V_{a}^{j}\left(m_{2}, a_{2}\right)=\phi_{3} E\left(\psi_{3}\right)+\sigma^{j}\left[\Delta^{j}+S(h)\right] \phi_{3} E\left(\psi_{3}\right)(1-h)
\end{aligned}
$$

So, depending on whether the non-negativity constraints are binding or not, agents' portfolio choice can lead to three different outcomes: only money, only asset, or both. By comparing the marginal rate of substitution (i.e. $V_{a}^{j} / V_{m}^{j}$ ) and the relative price (i.e. $\psi_{1}$ ), we get the following lemma.

Lemma 6. For a type $j=H, L$ agent, If $Q\left(\sigma^{j}\right)>\sigma^{j} \Delta^{j}$, then $a_{2}^{j}>0, m_{2}^{j}=0$; If $Q\left(\sigma^{j}\right)<\sigma^{j} \Delta^{j}$, then $a_{2}^{j}=0, m_{2}^{j}>0$; If $Q\left(\sigma^{j}\right)=\sigma^{j} \Delta^{j}$, then $a_{2}^{j}>0, m_{2}^{j}>0$; where $Q\left(\sigma^{j}\right)=\frac{E\left(\psi_{3}\right)\left[1+\sigma^{j} S(h)(1-h)\right]-\psi_{1}}{\psi_{1}-E\left(\psi_{3}\right)(1-h)}$

Finally, the envelope condition in the first subperiod is given by:

$$
\begin{aligned}
& Z_{m}\left(m_{1}, a_{1}\right)=\frac{1}{2} Z_{m}^{H}\left(m_{1}, a_{1}\right)+\frac{1}{2} Z_{m}^{L}\left(m_{1}, a_{1}\right)=\frac{1}{2}\left(\lambda^{H}+\lambda^{L}\right) \\
& Z_{a}\left(m_{1}, a_{1}\right)=\frac{1}{2} Z_{a}^{H}\left(m_{1}, a_{1}\right)+\frac{1}{2} Z_{a}^{L}\left(m_{1}, a_{1}\right)=\frac{1}{2} \psi_{1}\left(\lambda^{H}+\lambda^{L}\right)
\end{aligned}
$$


And the market clearing conditions are:

$$
\begin{aligned}
M & =\frac{1}{2} m_{2}^{H}+\frac{1}{2} m_{2}^{L} \\
A & =\frac{1}{2} a_{2}^{H}+\frac{1}{2} a_{2}^{L}
\end{aligned}
$$

We will now proceed to characterize the steady state equilibrium.

\subsection{Characterization of Equilibrium}

In this section, we will characterize the steady state equilibrium given the policy set by the government (i.e. the money supply $M$ and the money growth rate across periods $\gamma)^{15}$ and the stock of asset $A$. Below, the analysis will focus on the case in which liquidity constraints are binding for both types. Moreover, we are interested in symmetric steady state equilibria in which nominal prices are growing at the rate of money growth, and real quantities are constant over time: $\frac{\phi}{\phi_{+1}}=\frac{\psi_{+1}}{\psi}=\gamma$, and $q=q_{+1}$.

In particular, a steady state equilibrium can be defined as $\left(m_{2}^{H}, m_{2}^{L}, a_{2}^{H}, a_{2}^{L}\right.$, $\left.q^{H}, q^{L}, \phi_{3}, \psi_{1}, \psi_{3}, \lambda^{H}, \lambda^{L}\right)$ satisfying the following set of conditions. Let's first define some notation. Below, we will use superscript " $a$ " to denote the type who holds only assets, and use " $m$ " to denote the type who holds only money. In case one type holds both assets, w.l.o.g., we will use " $m$ " to denote $H$ and "a" to denote $L .{ }^{16}$

\footnotetext{
${ }^{15}$ Note that $\gamma$ is the rate of growth of money stock from one period to the next, which is a result of both lump-sum transfers and loan default.

${ }^{16}$ Both conditions (3.10) and (3.11) have to be satisfied for a type holding both money and asset.
} 
Equilibrium conditions are as follows:

$$
\begin{aligned}
\phi_{3} & =\beta Z_{+1, m}=\beta \frac{1}{2}\left(\lambda_{+1}^{a}+\lambda_{+1}^{m}\right) \\
q^{a} & =\phi_{3} m_{2}^{a}+\phi_{3} E\left(\psi_{3}\right) a_{2}^{a}(1-h) \\
q^{m} & =\phi_{3} m_{2}^{m}+\phi_{3} E\left(\psi_{3}\right) a_{2}^{m}(1-h) \\
m_{2}^{a}+m_{2}^{m} & =2 M \\
a_{2}^{a}+a_{2}^{m} & =2 A \\
\lambda^{m} & =V_{m}^{m}=\phi_{3}\left(1+\sigma^{m} \Delta^{m}\right) \\
\lambda^{a} & =V_{a}^{a} / \psi_{1}=\phi_{3} E\left(\psi_{3}\right)\left[1+\sigma^{a}\left(\Delta^{a}+S(h)\right)(1-h)\right] / \psi_{1} \\
m_{2}^{m}+\psi_{1} a_{2}^{m} & =M+\psi_{1} A \\
\psi_{3}(\delta) \phi_{3} & =\delta \\
Q\left(\sigma^{a}\right) & \geq \sigma^{a} \Delta^{a} \\
\sigma^{m} \Delta^{m} & \geq Q\left(\sigma^{m}\right)
\end{aligned}
$$

Here, (3.1) is the condition for the optimal money demand in the CM. (3.2) and (3.3) are the binding liquidity constraints in the DM. (3.4) and (3.5) are the market clearing conditions in the first subperiod AM. (3.6),(3.7), (3.10) and (3.11) are conditions for the optimal portfolio choice in the first subperiod. (3.8) is the budget constraint in the first subperiod. (3.9) is the market price of an asset that delivers $\delta$.

Defining $i$ as the (net) nominal interest rate, then the Fisher's equation and (3.1) imply

$$
1+i=\frac{\gamma}{\beta}=\frac{\phi_{3}}{\beta \phi_{3,+1}}=\frac{1}{2}\left(\frac{\lambda_{+1}^{m}+\lambda_{+1}^{a}}{\phi_{3,+1}}\right)
$$


(3.6) and (3.7) then imply

$$
1+i=\frac{1}{2}\left[\begin{array}{c}
\left\{1+\sigma^{m}\left[u^{\prime}\left(q^{m}\right)-1\right]\right\} \\
+\frac{E\left(\psi_{3,+1}\right)}{\psi_{1,+1}}\left\{1+\sigma^{a}\left[u^{\prime}\left(q^{a}\right)-1+S(h)\right](1-h)\right\}
\end{array}\right]
$$

The budget constraint, (3.8), implies the asset price is

$$
\psi_{1}=\frac{\left(m_{2}^{m}-M\right)}{\left(A-a_{2}^{m}\right)}
$$

Combining (3.2)-(3.5), (3.9) and (3.12) gives one equation in terms of $\left(\phi_{3}, m_{2}^{a}, a_{2}^{a}\right)$ :

$$
\begin{aligned}
& 1+i \\
= & \frac{1}{2}\left[\begin{array}{c}
\left\{1+\sigma^{m}\left[u^{\prime}\left(\phi_{3}\left(2 M-m_{2}^{a}\right)+\bar{\delta}\left(2 A-a_{2}^{a}\right)(1-h)\right)-1\right]\right\} \\
+\frac{\bar{\delta}}{\phi_{3} \psi_{1}}\left\{1+\sigma^{a}\left[u^{\prime}\left(\phi_{3} m_{2}^{a}+\phi_{3} E\left(\psi_{3}\right) a_{2}^{a}(1-h)\right)-1+S(h)\right](1-h)\right\} .
\end{array}\right],
\end{aligned}
$$

where $\psi_{1}=\frac{\left(m_{2}^{m}-M\right)}{\left(A-a_{2}^{m}\right)}$. We can now define the steady state equilibrium as follows.

Definition 7. A steady state monetary equilibrium consists of a price of money $\phi_{3}>0$ and a portfolio $\left(m_{2}^{a}, a_{2}^{a}\right)$ such that equation (3.14) and conditions (3.10)(3.11) are satisfied.

\subsection{Policy Constraint}

In the previous section, we characterize the set of equilibrium given any arbitrary policy $i$ (which is pinned down by the money growth rate $\gamma$ ) and $h$. However, not all $(i, h)$ policy pairs are feasible for the central bank to pick. In particular, the choice of $h$ will imply a minimum size of money injection, and thus a minimum level of interest rate $i$.

Note that whenever a borrower defaults his/her loan $l_{2}$, the new money temporarily lent out by the central bank in subperiod 2 will only be partially withdrawn by the central bank who sells the asset for $\psi_{3}(\delta)=\delta / \phi_{3}$ in subperiod 3. 
Lemma 3 implies that, for each unit of asset posted as collateral, the expected nominal size of default is

$$
E \max \left\{\psi_{2}(1-h)-\psi_{3}, 0\right\}=\frac{\bar{\delta}}{4 \phi_{3} \varepsilon}(\varepsilon-h)^{2} .
$$

Let $\bar{A}(h)$ be the amount of asset posted as collateral (as a function of the haircut policy), the money growth is equal to

$$
\gamma-1=\bar{A} \frac{\bar{\delta}}{4 M \phi_{3} \varepsilon}(\varepsilon-h)^{2}+\frac{\Delta M}{M} .
$$

The first term is the money injection due to unrepaid loans, and the second term is the lump sum transfers from the central bank in the third subperiod. We are going to restrict that the central bank does not possess any taxation power (i.e. $\Delta M \geq 0$ ). Therefore, there is a lower bound on the nominal interest rate, as summarized by the following proposition.

Proposition 8. Suppose the central bank does not have taxation power. The steady state nominal interest rate is subject to the constraint: $1+i=\frac{\gamma}{\beta} \geq$ $\bar{A} \frac{\bar{\delta}}{4 M \beta \phi_{3} \varepsilon}(\varepsilon-h)^{2}+\frac{1}{\beta}$.

\section{Simple Equilibrium}

In this section, we will first consider one simple equilibrium in which the $H$-type brings only money and the $L$-type brings only asset to the second subperiod. We will first derive some analytical results regarding the existence of the equilibrium and some comparative statics. Then we will use numerical examples to discuss the optimal haircut policy within this class of equilibria. Finally, we will look at two extensions: a non-exclusive lending facility, where both buyers and sellers have access to the facility; and a one-time temporary change in the haircut. 


\subsection{Existence and Comparative Statics}

A simple equilibrium is a symmetric steady state monetary equilibrium with $m_{2}^{H}=m_{2}^{m}=2 M, a_{2}^{H}=a_{2}^{m}=0$. For simplicity, assume that $u(q)=\log (q)$. Substituting these values in equations (3.13) and (3.14) yields the following result.

Proposition 9. Suppose $u(q)=\log (q)$. In a simple equilibrium,

(i) The equilibrium quantities are $q^{H}=2 M \phi_{3}$, and $q^{L}=2 A \bar{\delta}(1-h)$;

(ii) The equilibrium asset price in subperiod one is $\psi_{1}=\frac{M}{A}$.

(iii) The equilibrium price of money in subperiod three is

$$
=\frac{1}{2 M\left(1+2 i+\sigma^{H}\right)}\left[(1-\alpha)+2 \bar{\delta} A\left(1-\sigma^{L}\left[1-h-\frac{\bar{\delta}}{2 \varepsilon}(\varepsilon-h)^{2}\right]\right)\right]
$$

The welfare measured by ex-ante expected utility is

$$
W(i, h)=\sigma^{H}\left(\log \left(q^{H}\right)-q^{H}\right)+\sigma^{L}\left(\log \left(q^{L}\right)-q^{L}\right) .
$$

The policy constraint (3.15) is now given by

$$
i \geq \frac{\sigma^{L} A \bar{\delta}}{4 \beta M \phi_{3} \varepsilon}(\varepsilon-h)^{2}+\frac{1}{\beta}-1 .
$$

The welfare maximizing policy of the planner is a $(h, i)$ pair which maximizes $W(i, h)$ subject to the policy constraint (4.2).

We will first derive some comparative statics results when a simple equilibrium exists, and then provide sufficient conditions for the existence. The following proposition summarizes several comparative statics results.

Proposition 10. Suppose $u(q)=\log (q)$. In a simple equilibrium,

(i) $\frac{d_{\phi_{3}}}{d_{i}}<0, \frac{d_{q^{H}}}{d_{i}}<0, \frac{d_{q^{L}}}{d_{i}}=0$;

(ii) $\frac{d_{\phi_{3}}}{d h}>0, \frac{d_{q^{H}}}{d h}>0, \frac{d_{q^{L}}}{d h}<0$; 
(iii) $\frac{d_{\phi_{3}}}{d A \bar{\delta}}>0, \frac{d_{q}{ }^{H}}{d A \bar{\delta}}>0, \frac{d_{q^{L}}}{d_{A \bar{\delta}}}>0$;

(iv) $\frac{d_{\phi_{3}}}{d_{\varepsilon}}>0, \frac{d_{q} H}{d \varepsilon}>0, \frac{d_{q} L}{d \varepsilon}=0$;

\section{Effect of an increase in $i$}

Other things being equal, an increase in the interest rate $i$ lowers the equilibrium value of money $\left(\phi_{3}\right)$ (by (4.2)), and lowers the equilibrium consumption of the $H$-type $\left(q^{H}\right)$, and reduces the average welfare.

\section{Effect of an decrease in $h$}

A cut in the haircut $h$ relaxes the borrowing constraint of the $L$-type and thus increases the equilibrium consumption of the $L$-type $\left(q^{L}\right)$. Given that $\bar{\delta}<1$, a cut in haircut will lead to a lower $\phi_{3}$ and thus lower consumption of the $H$-type. ${ }^{17}$

If (4.2) is initially binding, a cut in $h$ will also tighten the policy constraint (by (4.2)), raising the lower-bound of the interest rate. Increasing $i$ will further reduce the consumption of the $H$-type.

Here, we can see that lowering the haircut has different effects on agents with different portfolio choices. On the one hand, it can relax the liquidity constraint of illiquid asset holders. On the other hand, it will lower the value of liquid assets (e.g. money) by both reducing the returns to holding liquidity and increasing the cost of holding liquidity (by increasing $i$ ). As a result, it will tighten the liquidity constraint of liquid asset holders.

\section{Effect of a drop in $\bar{\delta}$ or $A$}

A drop in $\bar{\delta}$ or $A$ will lower the consumption of the $L$-type, and it will also decrease the value of $\phi_{3}$ and thus lower the consumption of the $H$-type. If (4.2) is initially binding, it will relax the policy constraint and allow for a higher $h$ or a lower $i$.

\footnotetext{
${ }^{17}$ Proposition 11 argues that a simple equilibrium exists for $\alpha \rightarrow 0, \theta \rightarrow 0$, and $h \rightarrow \varepsilon$. Note that continuity is maintained as parameters converge to the this point. In particular, $q^{L}$ is the consumption of a low type conditional on being a buyer in the second subperiod. As $\alpha \rightarrow 0$ and $\theta \rightarrow 0$, the probability of a low type being a buyer converges to zero, but his consumption, $q^{L}$, conditional on being a buyer (which is zero probability event) is still strictly positive.
} 


\section{Effect of increase in $\varepsilon$}

An increase in $\varepsilon$ will not affect the consumption of the $L$-type, but it will increase the value of $\phi_{3}$ and thus increases the consumption of the $H$-type. If (4.2) is initially binding, it will tighten the policy constraint and require a higher $h$ or a higher $i$ to satisfy the policy constraint.

Now, we can show that the simple equilibrium exists under some conditions.

Proposition 11. Suppose $u(q)=\log (q)$, and $1-4 A \bar{\delta}(i(1-\varepsilon)-\varepsilon)<2 \bar{\delta} A<1$. There exists a simple equilibrium for $\alpha \rightarrow 0, \theta \rightarrow 0$, and $h \rightarrow \varepsilon$.

To show this, substitute the parameter values in lemma 6 to show that agents specialize in their portfolio choice. Then, proposition 9 is used to show that the liquidity constraint is binding, as asserted (see Appendix B). The idea is that, when the signal is almost perfect $(\theta \rightarrow 0)$, the $L$-type has no incentive to hold money for consumption. When the haircut is high $(h \rightarrow \varepsilon)$, the $H$-type does not have incentive to hold asset for consumption. Furthermore, the interest rate $i$ has to be high to make the liquidity constraints binding. Moreover, the real value of asset dividend $(\delta A)$ cannot be too high or too low. If it is too low, the $L$-type does not want to hold only assets. If it is too high, the $H$-type does not want to hold only money. ${ }^{18}$

\subsection{Numerical Examples}

In this section, we will use a numerical example to illustrate the model implications derived above. In particular, we will set the parameter values as follows: $M=1, A=7.5, \beta=0.94, \bar{\delta}=0.06, \varepsilon=0.4, \alpha=0.1, \theta=0.02$.

\footnotetext{
${ }^{18}$ Since the equations characterizing the equilibrium are continuous, and the conditions for specialized portfolios are satisfied with strict inequalities at this specific point, a simple equilibrium exists in the neighborhood of this subset of the parameter space.
} 


\section{Existence of Equilibrium}

The previous analysis shows that a simple equilibrium exists when equations (3.10), (3.11), (4.2) and condition (4.2) are all satisfied. Figure 4 shows the existence of equilibrium over the $(h, i)$ plain. In particular, equations (3.10), (3.11), (4.2) are satisfied inside the area bounded by the solid line. Condition (4.2) is satisfied for any $(h, i)$ pairs lying above the dotted curve. As shown above, the policy constraint is downward sloping. Therefore, inside the grey area, a simple equilibrium exists.

\section{Optimal Choice of Policy}

We now study the optimal policy within the set of simple equilibria. The optimal choice of $(h, i)$ depends on the objective function of the policy maker. The consumption of $H$-type is increasing in $h$ and decreasing in $i$. The consumption of $L$-type is decreasing in $h$ and is independent of $i$. In our example, the total output and the welfare are both decreasing in $h$ and $i$. Within the set of simple equilibria, in order to maximize the consumption of the $H$-type, the policy maker should choose $h=\varepsilon=0.4000$ and $i=0.0638$. Alternatively, a policy maker who wants to maximize the consumption of the $L$-type, the total output or the welfare should set $h=0.1480$ and $i=0.0646$.

\subsection{Extensions}

\section{Non-exclusive Lending Facility}

In the previous sections, it is assumed that only buyers have access to the central bank lending facility in the second sub-period. However, a seller might also have incentive to borrow from the central bank even though he does not want to consume. The idea is again that a loan collateralized on a risky asset with partial haircut provides an insurance for the borrower against the downside risk of the asset. If a seller obtains a collateralized loan from the central bank and 


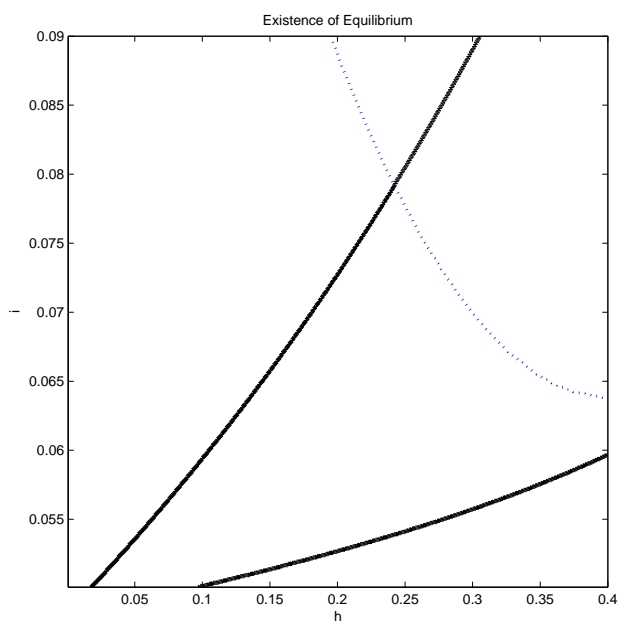

Figure 4: Existence of Equilibrium

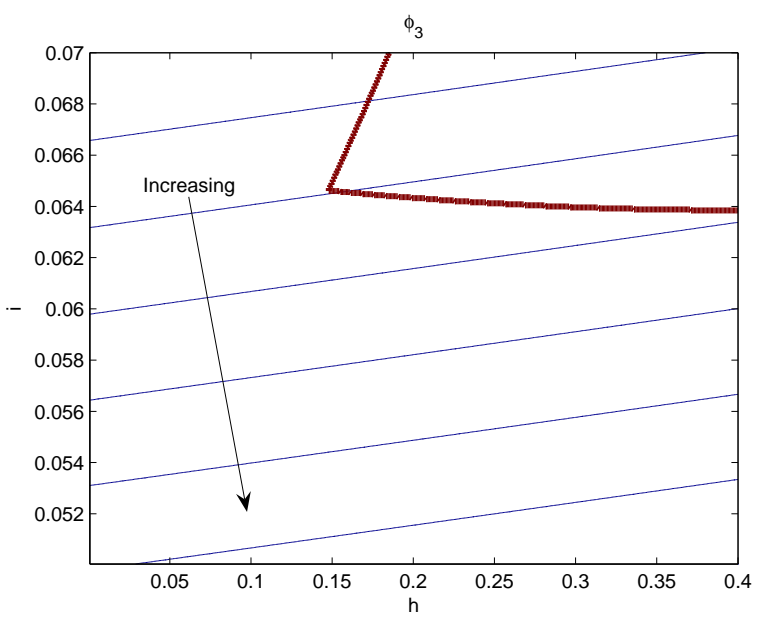

Figure 5: Real Price of Money

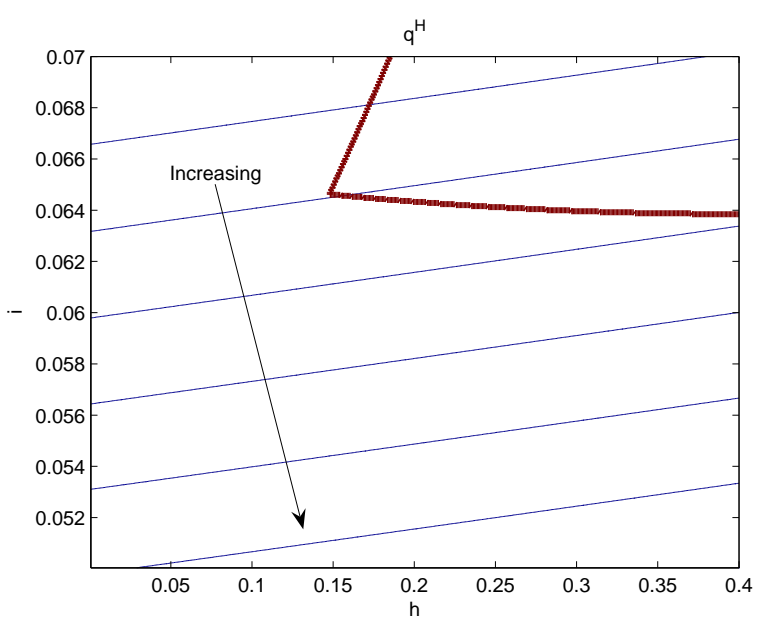

Figure 6: Consumption of $H$-type 


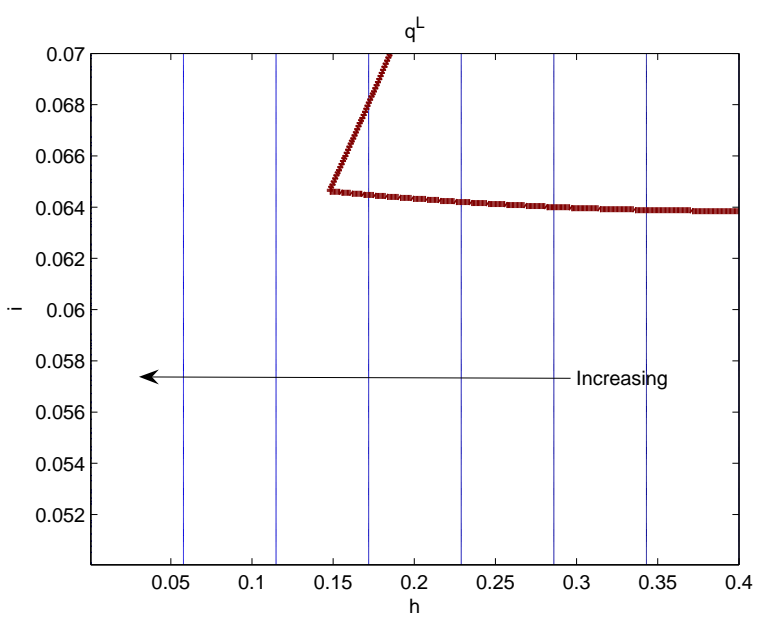

Figure 7: Consumption of $L$-type

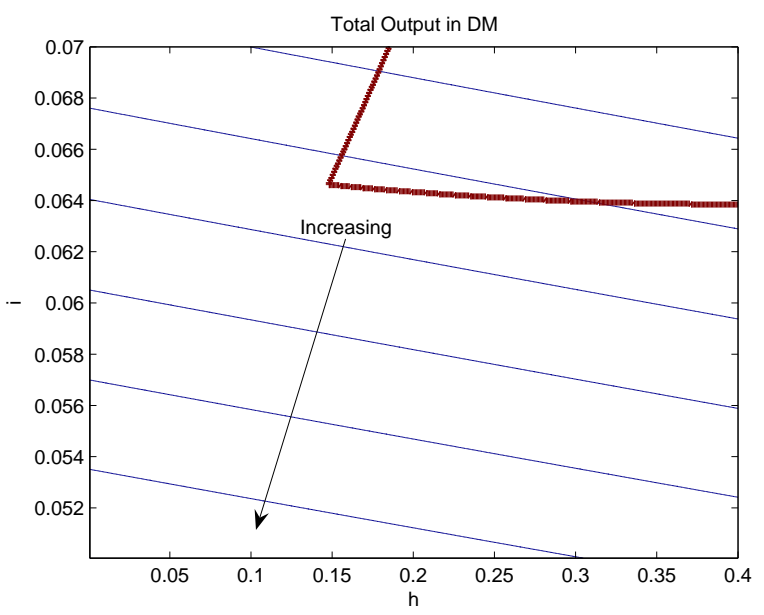

Figure 8: Total Consumption

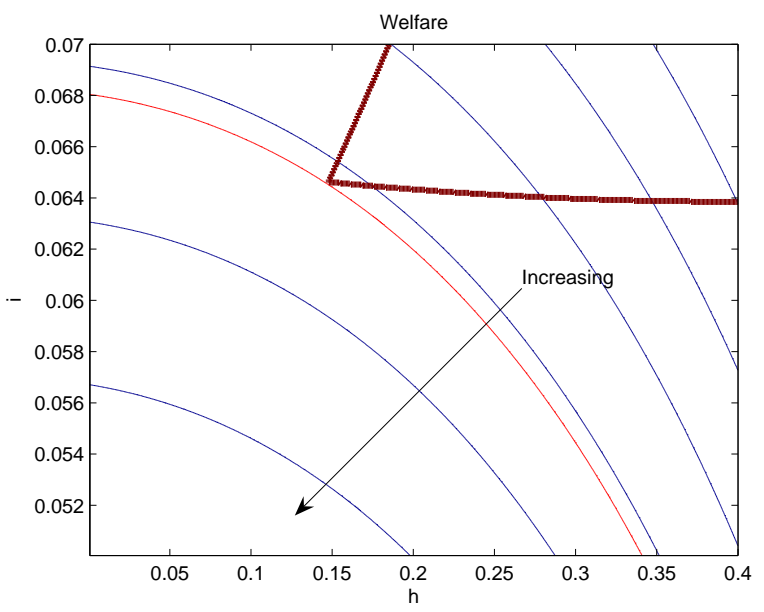

Figure 9: Welfare 
the price of the asset drops below the face value of the loan before repayment, then the seller has an option to default and shift the capital loss to the central bank. This option value depends on the haircut and is captured by the function $S(h)$. When the haircut is low, $S(h)$ is high and sellers have higher incentives to borrow from the central bank, even though they do not need to consume in the second-subperiod. In this section, we consider the case when the lending facility is available to both buyers and sellers. If the central bank is unable to exclude sellers from borrowing from the lending facility, then the equilibrium value of money is modified to

$\phi_{3}=\frac{1}{2 M\left(1+2 i+\sigma^{H}\right)}\left[1-\alpha+2 \bar{\delta} A\left(1-(1-h) \sigma^{L}\right)+\bar{\delta}^{2} A(1-\alpha)(\varepsilon-h)^{2}\right]$.

And the portfolio choice is also modified to

$$
Q\left(\sigma^{H}\right)=Q\left(\sigma^{L}\right)=\frac{E\left(\psi_{3}\right)[1+(1-\alpha) S(h)(1-h)]-\psi_{1}}{\psi_{1}-E\left(\psi_{3}\right)(1-h)}
$$

The policy constraint becomes

$$
i \geq \frac{(1-\alpha) A \bar{\delta}}{4 \beta M \phi_{3} \varepsilon}(\varepsilon-h)^{2}+\frac{1}{\beta}-1 .
$$

Comparing this policy constraint with constraint (4.2) suggests that the policy constraint is tightened when the central bank cannot restrict lending to the buyers only: the $i$ lower bound is higher for any given $h$, and the marginal effect of $h$ on the $i$ lower bound is higher. Therefore, in Figure 10, the feasible set of policy becomes smaller.

The welfare maximizing policy is given by $i=0.0671$ and $h=0.3264$. When the central bank cannot restrict lending, providing consumption insurance to the $L$-type by lowering the haircut $h$ becomes more costly in terms of distorting the $H$-type's consumption. 


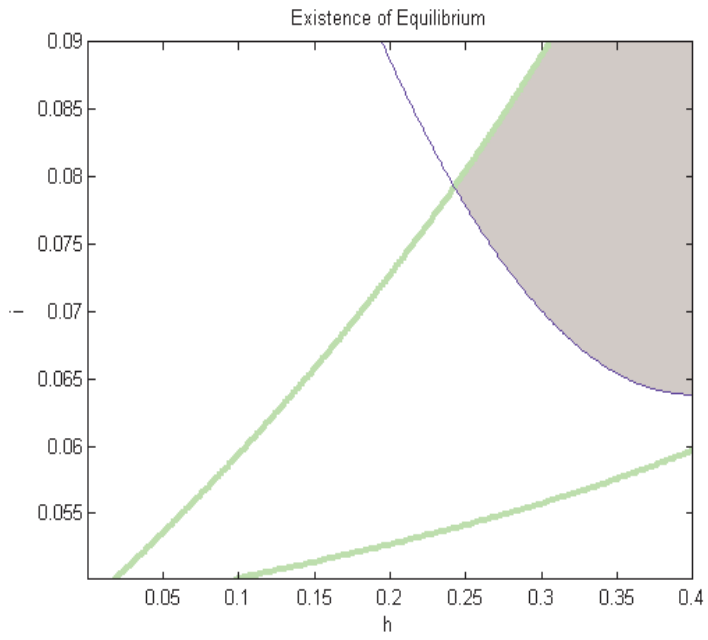

Figure 10: Non-exclusive Lending: Existence

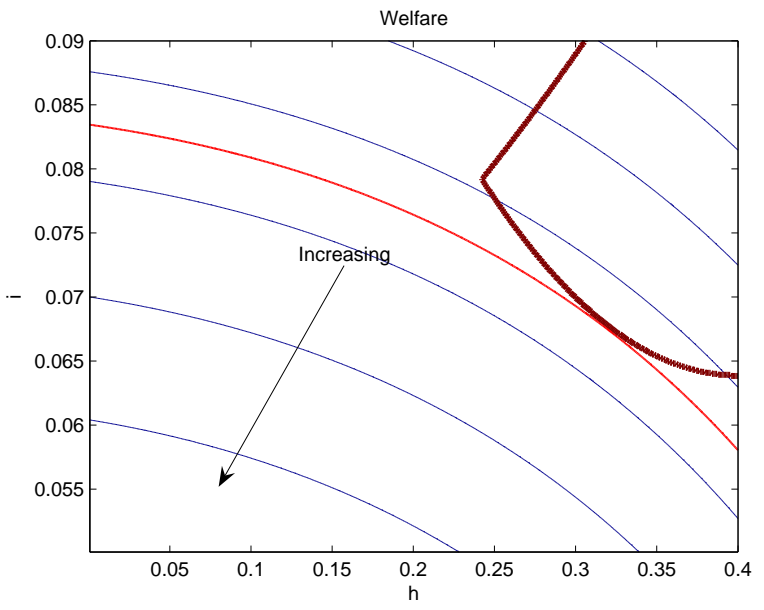

Figure 11: Non-exclusive Lending: Welfare

A policy implication is that the optimal haircut should depend on the features of the lending facility. When the central bank is about to lend exclusively to agents who are really in need of liquidity, then the haircut can be set more generously, relative to a situation where the central bank cannot exclude borrowers who are not constrained but borrow only to take advantage of the insurance against the downside risk of the collateral asset. 


\section{Temporary versus Permanent Change in Haircut}

In the previous section, we consider optimal permanent changes in haircut. Here, we study how a one-time change in haircut can improve on the allocation temporarily.

Here, we consider the case in which the central bank can exclude borrowing from the sellers. Suppose the central bank is following the optimal policy (i.e. $h=0.1480, i=0.0646)$ and is allowed to make one-time change in $h$ in the current period (with the agents believing the central bank will bring the $(i, h)$ back to the original levels before the change).

Since this is a one-time change in $h$, it will have no effect on future allocation. In particular, it will not affect the policy constraint (4.2). The only effect is on the current stock of money supply and on the current price of money in the third subperiod. Denoting $\tilde{h}$ as the haircut in the current period, the current period equilibrium $\left\{\phi_{3}(\tilde{h}), \Delta M(\tilde{h}), q^{H}(\tilde{h}), q^{L}(\tilde{h})\right\}$ is then determined by

$$
\begin{aligned}
\phi_{3}(\tilde{h}) & =\frac{(1-\alpha)+2 \bar{\delta} A\left(1-\sigma^{L}\left[1-h-\frac{\bar{\delta}}{2}(\varepsilon-h)^{2}\right]\right)}{2(M+\Delta M(\tilde{h})) / \gamma\left(1+2 i+\sigma^{H}\right)} \\
\Delta M(\tilde{h}) & =\frac{\sigma^{L} A \bar{\delta}}{4 \phi_{3} \varepsilon}(\varepsilon-\tilde{h})^{2} \\
q^{H}(\tilde{h}) & =2 M \phi_{3}(\tilde{h}) \\
q^{L}(\tilde{h}) & =2 A \bar{\delta}(1-\tilde{h}) .
\end{aligned}
$$

As shown in Figure (12), it is welfare maximizing to temporarily lower the haircut from $h=0.1480$ to $h=-0.0 .0452$. Note that the optimal one-period deviation of the haircut is indeed negative to improve ex-post efficiency. This will temporarily increase the money stock (additionally by $0.16 \%$ ), lower the price of money (by $0.15 \%$ ), increase the consumption of the $L$-type (by $22.68 \%$ ) and lower the consumption of the $H$-type (by $0.15 \%$ ).

In the table, we also report the case of a one-time change in the haircut in 

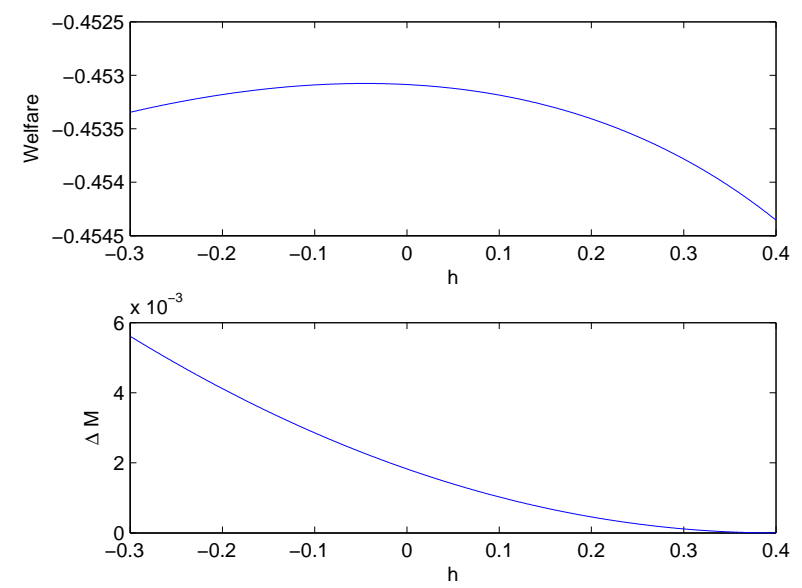

Figure 12: One-time Change in Haircut: Welfare and Change in Money Stock the case of non-exclusive lending facilities. As expected, in this case, it is not optimal to lower the haircut by too much.

Table 1: Optimal Permanent and Temporary Haircut

\begin{tabular}{|l|c|c|c||c|c|}
\hline & $h$ & $i$ & $W$ & $\tilde{h}$ & $\tilde{W}$ \\
\hline Exclusive Lending & 0.1480 & 0.0646 & -0.4533 & -0.0452 & -0.4531 \\
\hline Non-Exclusive Lending & 0.3264 & 0.0671 & -0.4540 & 0.3128 & -0.4540 \\
\hline
\end{tabular}

A policy implication is that a one-time, unanticipated reduction in the haircut is less distortionary than a permanent change. This may provide the central bank with a tool to improve allocation in response to temporary shocks (e.g. temporary aggregate shocks to liquidity). Of course, this raises issues related to the commitment of the central bank.

\section{Portfolio Distortion and Optimal Policy}

The previous sections focused on the analysis of a simple equilibrium in which agents specialize in their portfolio choice. This section will examine how central bank policy can affect agents' portfolio choice and the welfare.

Figure 13 plots the equilibrium outcomes for different policy combinations of $h$ and $i$. The two upward sloping lines partition the $h-i$ space into three 


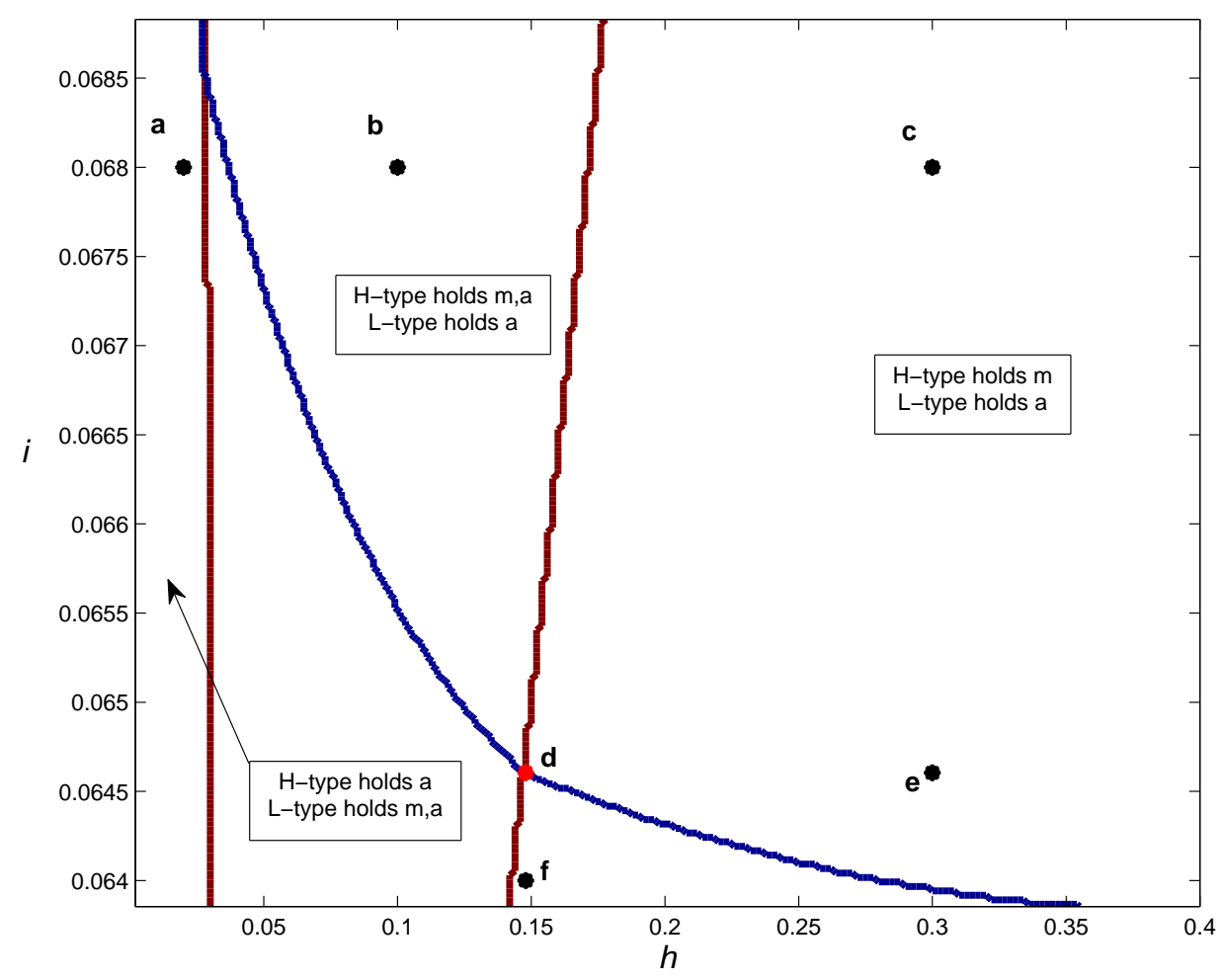

Figure 13: Policy and Portfolio Distortion

subsets, each of which denotes a different equilibrium portfolio choice. The downward sloping curve indicates the policy constraint faced by the central bank. The points $a$ to $f$ denote different portfolio choice examples which we will discuss below. ${ }^{19}$ Table 2 reports the effects of policy on the default option value, portfolio, consumption, and welfare at these different points in the $h-i$ space.

First, we examine the effect of lowering the haircut policy, holding the interest rate fixed.

When the haircut $h$ is high (the right portion of the graph), the $H$-type will bring only money to the second subperiod, and the $L$-type will bring only asset to the second subperiod. This corresponds to the simple equilibrium discussed

\footnotetext{
${ }^{19}$ Note that points $a$ and $f$ are not implementable if the central bank cannot withdraw money from the economy because they violate the policy constraint. Indeed, the whole area under the downward sloping policy constraint is not implementable.
} 
Table 2: Effects of Policy

\begin{tabular}{c|cccccccccc}
\hline & $h$ & $i$ & $S(h)$ & $m^{H}$ & $a^{H}$ & $m^{L}$ & $a^{L}$ & $q^{H}$ & $q^{L}$ & $W$ \\
\hline \hline$a$ & $2 \%$ & $6.80 \%$ & 0.0921 & 0 & 14.7800 & 2 & 0.2154 & 0.8693 & 0.8868 & -0.4542 \\
$b$ & $10 \%$ & $6.80 \%$ & 0.0625 & 2 & 0.2213 & 0 & 14.7787 & 0.8776 & 0.7980 & -0.4538 \\
$c$ & $30 \%$ & $6.80 \%$ & 0.0089 & 2 & 0 & 0 & 15 & 0.8863 & 0.6300 & -0.4539 \\
$d$ & $14.8 \%$ & $6.46 \%$ & 0.0466 & 2 & 0 & 0 & 15 & 0.8881 & 0.7668 & -0.4533 \\
$e$ & $30 \%$ & $6.46 \%$ & 0.0089 & 2 & 0 & 0 & 15 & 0.8890 & 0.6300 & -0.4538 \\
$f$ & $14.8 \%$ & $6.40 \%$ & 0.0466 & 2 & 0 & 0 & 15 & 0.8887 & 0.7668 & -0.4532 \\
\hline \hline
\end{tabular}

in the previous section. An example is point $c$ in the figure.

For lower haircut (the middle portion of the graph), the $H$-type is induced to hold both money and asset because of the higher value of the "default option". For example, relative to point $c$, the haircut at point $b$ is lower while the interest rate is the same. As shown in the table, when $h$ goes down, $S(h)$ rises, and the $H$-type is induced to hold more asset. As a result, the consumption of the $H$-type goes down, and that of the $L$-type goes up, leading to a higher welfare level.

For even lower haircut (the left portion of the graph), the "default option" is so attractive that the $H$-type chooses to hold only asset, and the $L$-type will hold both money and asset. Since the $H$-type is more likely to acquire the collateralized loan, the asset has higher value to them than to the $L$-type (as illustrated by the envelope condition in Lemma 5). For example, relative to point $b$, the haircut at point $a$ is lower while the interest rate is the same. As shown in the table, when $h$ goes down, $S(h)$ rises further, and the $H$-type is induced to hold only asset. As a result, the consumption of the $H$-type goes down, and that of the $L$-type goes up. Since the $H$-type is more likely to consume, this further distortion of their portfolio reduces the welfare level.

Now, we examine the effect of lowering the interest rate, holding the haircut policy fixed. Relative to point $c$, the interest rate is lower at point $e$ while the haircut is the same. This will lower the opportunity cost of holding money and 
increase the equilibrium purchasing power of money, allowing the $H$-type to consume more. As a result, the welfare level goes up.

The optimal policy combination will take into account the effects above as well as the policy constraint. Point $d$ indicates the welfare-maximizing policy which is given by $h=0.148$ and $i=0.0646$. Finally, at point $f$ the interest rate is further reduced and the welfare is even higher. However this policy combination is not feasible because it violates the policy constraint: the haircut is too low for supporting that interest rate in equilibrium.

The previous discussion highlights the trade-off faced by the central bank when setting the optimal policy combination of haircuts and interest rate. On the one hand, lowering the haircut can provide more liquidity insurance to constrained agents. On the other, it will also provide more insurance against the downside risk of the illiquid asset, as captured by $S(h)$. The first insurance is welfare improving, but the latter insurance can distort agents' portfolio choice and can tighten the central bank's policy constraint. The haircut and the interest rate have to be set optimally to balance these two effects.

\section{Discussion}

In the model, we have assumed a constant supply of illiquid assets and studied the effect of haircut policy on the price of these assets. In this section, we endogenize the amount of the pledgable asset and discuss the equilibrium response to changes in haircut policy. To obtain an analytical solution, we will first focus on the simple equilibria in which agents specialize in their portfolio choice. We will then consider the general case by studying a numerical example.

Suppose there is no endowment of illiquid assets. Instead, in the (sub-period 3) centralized market of period $t$, agents have to choose how much illiquid asset, $A_{+1}$, to be produced for the next period. As before, each of these assets will yield random real dividend $\delta$ at the end of the period $t+1 \mathrm{CM}$. The cost of 
producing $A$ units of illiquid asset is give by $C(A)=(\bar{\delta}+\tau) A$, with $\tau>0$. Note that the asset is non-productive because the per-unit cost is higher than the expected return of the dividend. The problem becomes

$$
W(y)=\max _{H_{3}, m_{+1}}-H_{3}+\beta Z_{+1}\left(m_{+1}, A_{+1}\right)
$$

subject to

$$
-H_{3}=y_{3}-\phi_{3} m_{+1}-C\left(A_{+1}\right)+\phi_{3} \Delta M
$$

Here, $\Delta M=M_{+1}-M_{3}$ with $M_{3}$ and $M_{+1}$ being the total money stock at the beginning and at the end of subperiod 3 respectively. The linearity of utility implies that

$$
W\left(y_{3}\right)=\max _{m_{+1}} y_{3}-\phi_{3} m_{+1}-C\left(A_{+1}\right)+\phi_{3} \Delta M+\beta Z_{+1}\left(m_{+1}, A_{+1}\right)
$$

F.O.C.:

$$
\begin{aligned}
& m_{+1}: \quad \phi_{3} \geq \beta \frac{\partial}{\partial m_{+1}} Z_{+1}\left(m_{+1}, A_{+1}\right),=\text { if } m_{+1}>0 \\
& A_{+1}: \quad C^{\prime}\left(A_{+1}\right) \geq \beta \frac{\partial}{\partial A_{+1}} Z_{+1}\left(m_{+1}, A_{+1}\right),=\text { if } \quad A_{+1}>0
\end{aligned}
$$

Consider an equilibrium with $A_{+1}>0$ and $m_{+1}>0$. All other decision are not affected. In particular, the envelope conditions in the first subperiod are still given by:

$$
\begin{aligned}
Z_{m}\left(m_{1}, a_{1}\right) & =\frac{1}{2}\left(\lambda^{H}+\lambda^{L}\right) \\
Z_{a}\left(m_{1}, a_{1}\right) & =\frac{1}{2} \psi_{1}\left(\lambda^{H}+\lambda^{L}\right)
\end{aligned}
$$

The euler equations of money and illiquid assets are then given by 


$$
\begin{aligned}
\phi_{3} & =\beta \frac{1}{2}\left(\lambda_{+1}^{a}+\lambda_{+1}^{m}\right) \\
C^{\prime}\left(A_{+1}\right) & =\beta \frac{1}{2} \psi_{1,+1}\left(\lambda_{+1}^{a}+\lambda_{+1}^{m}\right)=\psi_{1,+1} \phi_{3}
\end{aligned}
$$

The following equations then characterize a simple equilibrium:

(i) The equilibrium quantities are $q^{H}=2 M \phi_{3}$, and $q^{L}=2 A \bar{\delta}(1-h)$;

(ii) The equilibrium asset price in subperiod one is $\psi_{1}=\frac{M}{A}$.

(iii) The equilibrium price of money in subperiod three and the amount of asset is

$$
\begin{aligned}
\phi_{3} & =\frac{1}{2 M\left(1+2 i+\sigma^{H}\right)}\left[(1-\alpha)+2 \bar{\delta} A\left(1-\sigma^{L}\left[1-h-\frac{\bar{\delta}}{2 \varepsilon}(\varepsilon-h)^{2}\right]\right)\right] \\
\phi_{3} & =C^{\prime}(A) \frac{A}{M \gamma}
\end{aligned}
$$

Consider $\phi_{3}$ as functions of $A$ in the previous two equations. It is straightforward to show that the difference between the two functions is monotonically decreasing in $A$ and there is a unique solution $\left(\phi_{3}, A\right)$ solving the two equations. Also, focusing on simple equilibrium with interior solution, it is easy to show that $\frac{\mathrm{d} \phi_{3}}{\mathrm{~d} h}>0, \frac{\mathrm{d} A}{\mathrm{~d} h}>0$. The idea is that, increasing haircuts tighten the liquidity constraint of buyers in the second sub-period. This will increase the price of money. Since money and asset are substitutes, agents are induced to produce more illiquid assets.

We now use an numerical example to illustrate the general effects of changing the haircut. In this numerical example, we set $\tau=0.001$. As reported in the following table, an increase in $h$ again tightens agents' liquidity constraint and induces higher investment in the non-productive illiquid asset.

A full characterization of the equilibria and optimal haircut policy in this environment has proven technically very challenging and is left for future research. 


\begin{tabular}{llllll}
\hline$h$ & $i$ & $A$ & $a^{H}$ & $a^{L}$ & $W$ \\
\hline \hline 0.1 & $1 \%$ & 7.0198 & 14.0153 & 0.0243 & -0.4646 \\
0.2 & $1 \%$ & 7.0657 & 14.1314 & 0 & -0.4645 \\
0.3 & $1 \%$ & 7.0776 & 14.1552 & 0 & -0.4649 \\
0.4 & $1 \%$ & 7.0895 & 14.1790 & 0 & -0.4654 \\
0.5 & $1 \%$ & 7.1017 & 14.2034 & 0 & -0.4661 \\
\hline \hline
\end{tabular}

\section{Conclusion}

We have developed a model of central bank lending to study the optimal choice of haircut policy. We found that, in the presence of liquidity shocks, credit market imperfections and asset price uncertainty, there is a trade-off between relaxing the liquidity constraints of agents, and increasing potential inflation risk and distorting the portfolio choices of agents. The lending facility provides a bundle of two types of insurance: an insurance against liquidity risk and an insurance against the downside risk of the illiquid asset.

Furthermore, we show that the optimal haircut is higher when the central bank is unable to lend exclusively to agents who actually need liquidity. Also, for a temporary surprise drop in the haircut, the central bank can be more aggressive than when setting a permanent level of the haircut. Finally, we endogenize the amount of pledgable asset and illustrate how an increase in haircut can tighten agents' liquidity constraints and induce a higher investment in non-productive pledgable assets.

We have studied stationary environments and abstracted from aggregate uncertainty. An interesting question left for future research is to analyze the optimal haircut policy in the presence of cyclical fluctuations. 


\section{Appendix A: Value of Default Option}

A borrower with a loan $l_{2}$ can choose to repay the loan and get back the collateral (with a price $\psi_{3}$ ) or to default and lose the asset. Therefore, the expected value of this default option is

$$
\begin{aligned}
& l_{2} E \max \left\{\phi_{3}-\frac{\phi_{3} \psi_{3}}{\psi_{2}(1-h)}, 0\right\} \\
= & \frac{\phi_{3} l_{2}}{\bar{\delta}(1-h)} E \max \{\bar{\delta}(1-h)-\delta, 0\} \\
= & \frac{\phi_{3} l_{2}}{2 \varepsilon \bar{\delta}^{2}(1-h)} \int_{\bar{\delta}(1-\varepsilon)}^{\bar{\delta}(1-h)}[\bar{\delta}(1-h)-\delta] d \delta \\
= & \frac{\phi_{3} l_{2}}{4 \varepsilon(1-h)}(\varepsilon-h)^{2} .
\end{aligned}
$$

The first equality is a result of Lemma 1 and 2. The second equality comes from the distributional assumption.

\section{Appendix B: Proof of Proposition 11}

To prove: Suppose $u(q)=\log (q)$, and $1-4 A \bar{\delta}(i(1-\varepsilon)-\varepsilon)<2 \bar{\delta} A<1$. There exists a simple equilibrium for $\alpha \rightarrow 0, \theta \rightarrow 0$, and $h \rightarrow \varepsilon$.

Proof: Note that $\sigma^{H} \rightarrow 1, \sigma^{L} \rightarrow 0$ and $S(h) \rightarrow 0$. Also, in a simple equilibrium, $q^{H}=2 M \phi_{3}$ and $q^{L}=2 A \bar{\delta}(1-h)$. The equilibrium price of money is then given by

$$
\phi_{3} \rightarrow \frac{1+2 \bar{\delta} A}{4 M(1+i)}
$$

The consumption quantities are

$$
\begin{aligned}
q^{H} & \rightarrow \frac{1+2 \bar{\delta} A}{2(1+i)} \\
q^{L} & \rightarrow 2 A \bar{\delta}(1-h)
\end{aligned}
$$


The asset prices are

$$
\begin{aligned}
\psi_{1} & =\frac{M}{A} \\
E\left(\psi_{3}\right) & =\psi_{2} \rightarrow \frac{4(1+i) M \bar{\delta}}{1+2 \bar{\delta} A} .
\end{aligned}
$$

First, we need to check the incentive of the low type to hold only asset:

$$
\begin{aligned}
& E\left(\psi_{3}\right)\left[1+\sigma^{L} S(h)(1-h)\right]-\psi_{1}-\sigma^{L} \Delta^{L}\left(\psi_{1}-E\left(\psi_{3}\right)(1-h)\right) \\
\rightarrow & {[2 \bar{\delta} A-(1-4 i \bar{\delta} A)] \frac{M}{A(1+2 \bar{\delta} A)}>0, }
\end{aligned}
$$

which is satisfied if $2 \bar{\delta} A>1-4 i \bar{\delta} A$. Similarly, one can show that, if $1-4 A \bar{\delta}(i(1-$ $\varepsilon)-\varepsilon)<2 A \bar{\delta}$, then high types want to hold only money. Finally, one has to check that $q^{H}, q^{L}$ are constrained, and these conditions are satisfied if $2 A \bar{\delta}<1$. 


\section{References}

Berentsen, A. And C. Monnet (2008): "Monetary Policy in a Channel System," Journal of Monetary Economics, 55, 1067-1080.

Bhattacharya, J., J. Haslag, and A. Martin (2009): "Why Does Overnight Liquidity Cost More Than Intraday Liquidity?" Journal of Economic Dynamics and Control, 33, 1236-1246.

Chapman, J. T. And A. Martin (2007): "Rediscounting Under Aggregate Risk With Moral Hazard," Federal Reserve Bank of New York Staff Report No. 296 and Bank of Canada Working Paper 2007-51.

Garcia, A. And R. GençAy (2006): "Risk-Cost Frontier and Collateral Valuation in Securities Settlement Systems for Extreme Market Events," Bank of Canada Working Paper No. 2006-17.

Khan, C. (2008): "Offshore Settlement, Collateral, and Interest Rates," Mimeo.

Lacker, J. M. (2001): "Collateralized Debt as the Optimal Contract," Review of Economic Dynamics, 4, 842-859.

Lagos, R. And R. Wright (2005): "A Unified Framework for Monetary Theory and Policy Analysis," Journal of Political Economy, 113, 463-484.

Martin, A. And J. McAndrews (2008): "Should There Be Intrday Money Markets?" FRB New York Staff Report No. 337.

Martin, A. And C. Monnet (2008): "Monetary Policy Implementation Framewokrs: A Comparative Analysis," FRB New York Staff Report No. 313.

SuÁrez-Lledó, J. (2009): "Monetary Policy with Heterogeneous Collateralized Borrowing," Mimeo Univeridad Autónoma of Barcelona. 